\title{
Impact of Meyerozyma guilliermondii isolated from chickens against Eimeria sp. protozoan, an in vitro analysis
}

\author{
Edgar Dantán-González ${ }^{1 *}$, Rosa Estela Quiroz-Castañeda², Mayra Cobaxin-Cárdenas', Jorge Valle-Hernández ,
} Yitzel Gama-Martínez ${ }^{3}$, José Raunel Tinoco-Valencia ${ }^{4}$, Leobardo Serrano-Carreón ${ }^{4}$ and Laura Ortiz-Hernández ${ }^{1}$

\begin{abstract}
Background: Avian coccidiosis is a disease caused worldwide by several species of parasite Eimeria that causes significant economic losses. This disease affects chickens development and production, that most of times is controlled with anticoccidial drugs. Although efforts have been made to address this disease, they have been made to control Eimeria sporozoites, although enteric stages are often vulnerable, however; the parasite oocyst remains a problem that must be controlled, as it has a resistant structure that facilitates dispersion. Despite some commercial products based on chemical compounds have been developed as disinfectants that destroy oocysts, the solution of the problem remains to be solved.

Results: In this work, we assessed in vitro anticoccidial activity of a compound(s) secreted by yeast isolated in oocysts suspension from infected chickens. The yeast was molecularly identified as Meyerozyma guilliermondii, and its anticoccidial activity against Eimeria tenella oocysts was assessed. Here, we report the damage to oocysts walls caused by M. guilliermondii culture, supernatant, supernatant extract and intracellular proteins. In all cases, a significant decreased of oocysts was observed.

Conclusions: The yeast Meyerozyma guilliermondii secretes a compound with anticoccidial activity and also has a compound of protein nature that damages the resistant structure of oocyst, showing the potential of this yeast and its products as a feasible method of coccidiosis control.
\end{abstract}

Keywords: Avian coccidiosis, Oocyst, Meyerozyma guilliermondii, Anticoccidial

\section{Background}

Coccidiosis is a widespread disease reported in numerous vertebrate that is caused by Eimeria species and shows strict host specificity [1]. In the poultry industry, which raises approximately 40 billion chickens annually, coccidiosis represents a serious disease that results in annual global economic losses of approximately $\$ 2.4$ billion, including production losses and prevention and treatments costs [2-4].

Chicken coccidiosis is caused by Eimeria species that belongs to Apicomplexa, a phylum that includes veterinary and medical significance protozoa such as Cryptosporidium,

\footnotetext{
* Correspondence: edantan@uaem.mx

'Laboratorio de Investigaciones Ambientales-Centro de Investigación en Biotecnología, Universidad Autónoma del Estado de Morelos, Cuernavaca, Morelos, Mexico

Full list of author information is available at the end of the article
}

Neospora, Plasmodium, and Toxoplasma [2]. Eimeria invade and destroy the intestinal epithelium of chickens, as a consequence infected birds display reduced feed intake, bloody diarrhea and hampered weight gain $[5,6]$.

Coccidiosis in chickens is a complex disease caused by one or more of several Eimeria species [7].

It has been reported that about 1800 Eimeria spp can affect the intestinal mucosa of mammals and birds, but only seven species are considered the causative agent of avian coccidiosis: E. tenella, E. necatrix, E. acervulina, E, maxima, E. brunetti, E. mitis and E. praecox [8].

Eimeria spp. has a complex life cycle, during which a resistant bilayered structure called oocyst is formed. The oocyst is non-infective when is unsporulated inside the chicken turning to infective when is sporulated, which occurs in the environment $[2,9]$. 
The oocyst is considered a remarkably hard and persistent structure due to its composition of proteins, carbohydrate and lipids, which varies among species. It is also relatively resistant to mechanical and chemical damage, and to proteolytic degradation [10-12].

Coccidiosis disease control efforts have been focused on the development of several anticoccidials (ionophores and synthetic chemicals) that have been mainly directed to the parasites during the sexual and asexual stages that occur within the host rather than targeting the most infectious stage, the oocyst [13].

Due to anticoccidial drug resistance observed in birds around the world, a search for natural products with anticoccidial action has emerged, including fungi, plants and essential oils (oregano, laurel leaf, lavender, artemisia, clove, and tea tree) [14-18]. Recently, [19] described a list with natural products commercially available.

Despite the anticoccidial activity observed for natural products, the elevated cost of farming and production required to obtain sufficiently large quantities make their use impractical as a strategy to control coccidiosis in large population of birds.

With the aim of finding effective anticoccidial products that can be an alternative to anticoccidial reported, in this work, we isolated a yeast from an oocyst suspension from infected chickens and identified by molecular methods as Meyerozyma guilliermondii 01. We observed a surprising anticoccidial activity in the yeast culture, yeast culture medium supernatant and ethyl acetate extract of the supernatant, all have the ability to break oocysts, the strongest structures made by different species of Eimeria. Interestingly, the damage caused by M. guilliermondii 01 involves destruction of the oocyst wall and weakening of its structure, and thus reducing the probability of infection. The newfound anticoccidial activity of $M$. guilliermondii 01 might have implications for the development of novel anticoccidial control drugs.

\section{Methods}

\section{Isolation of Meyerozyma guilliermondii}

The yeast $M$. guilliermondii was isolated from oocyst suspensions recovered from ATD-1Coccivac B (MSD Animal Health), a commercial vaccine of live oocysts ( $E$. acervulina, E.mivati, E.maxima and E. tenella). This vaccine is produced by Merck, a company that is intended to use ethically resources to fulfill customers expectative, they are adhere to: the International Federation for Animal Health Statement of Principles; the US-bases Animal Health Institute Advertising Guidelines; The UK-based National Office of Animal Health Code of Practice for the Promotion of Animal Medicine.

A loopful of a suspension was used to inoculate Petri dishes $(90 \times 15 \mathrm{~mm}$, Ruisanchez, Mexico $)$ of YPDA medium (Yeast extract, Peptone, Dextrose, Agar) [20 g/
L yeast extract (BD, USA), $5 \mathrm{~g} / \mathrm{L}$ peptone (BD Difco, USA), $40 \mathrm{~g} / \mathrm{L}$ dextrose (Fermont, Mexico), $10 \mathrm{~g} / \mathrm{L}$ agar (BD, USA)]; the plates were incubated (LabTech 3016A, USA) at $28{ }^{\circ} \mathrm{C}$ for $16 \mathrm{~h}$. After the incubation, yeast colonies were observed, picked and grown in liquid YPD (Yeast extract, Peptone, Dextrose) [20 g/L yeast extract (BD, USA), $5 \mathrm{~g} / \mathrm{L}$ peptone (BD Difco, USA), $40 \mathrm{~g} / \mathrm{L}$ dextrose (Fermont, Mexico)] under the same conditions for further identification. Solid YPD was used only to grow and preserve yeast for a short period of time at $4{ }^{\circ} \mathrm{C}$ on a Petri dish. A loopful from this plate was used to cultivate M. guilliermondii in liquid YPD to perform the bioassays.

\section{Obtaining of oocysts used in bioassays}

Eimeria tenella oocyst suspensions were obtained from infected chickens and maintained in potassium dichromate at $4{ }^{\circ} \mathrm{C}$. E. tenella oocysts were kindly provided by SENASICA (Servicio Nacional de Sanidad Inocuidad y Calidad Agroalimentaria,). All protocols used in this study were approved by the animal ethics committee of National Commission on Bioethics (http://www.conbioetica-mexico.salud.gob.mx/) consistent with the recommendations of the Mexican Official Standard NOM-062-ZOO-1999, Technical Specifications for the production, care and use of laboratory animals.

Eimeria spp. oocysts were obtained from commercial vaccine Autocox (Eimeria, Mexico) that contains oocysts from E. acervulina, E. maxima, E. tenella and E. praecox. Eimeria S.A de C.V., is certified by Secretaría de Agricultura, Ganadería, Desarrollo Rural, Pesca y Alimentación (SAGARPA, México) since it fulfills the requirement of good practices in manufacture of the vaccines contained in NOM-022-ZOO-1995 y NOM-026-ZOO-1994.

\section{Amplification by PCR of 5.8S-ITS rDNA region of $M$. guilliermondii}

Yeast cells were grown on YPDA medium at $28{ }^{\circ} \mathrm{C}$ for $48 \mathrm{~h}$. Cells were collected with the tip of a toothpick and directly used for polymerase chain reaction (PCR).

To amplify the 5.8S-ITS rDNA region and the D1/D2 domain, a PCR reaction was performed as reported by [20]. Thermal cycling was conducted with an initial step at $95{ }^{\circ} \mathrm{C}$ for $5 \mathrm{~min}, 40$ cycles of $94{ }^{\circ} \mathrm{C}$ for $40 \mathrm{~s}, 55^{\circ} \mathrm{C}$ for $40 \mathrm{~s}$ and $72{ }^{\circ} \mathrm{C}$ for $30 \mathrm{~s}$ and a final extension of $10 \mathrm{~min}$ at $72{ }^{\circ} \mathrm{C}$.

Amplification of the 5.8S-ITS rDNA region was achieved with the primers reported by [21]: its1 (5'TCCGTAGGTGAACCTGCGG-3') and its4 (5'-TCCT CCGCTTATTGATATGC-3'). Amplification of the D1/ D2 domain of the 26S rRNA gene was achieved with the primers NL1 (5'GCATATCAATAAGCGGAGGAA AAG-3') and NL4 (5'-GGTCCGTG TTTCAAGAC GG-3') [22]. 
After PCR, the 620-bp amplification products were excised from a $1 \%$ agarose gel and purified using a High Pure PCR Product Purification Kit (Roche, USA) according to the manufacturer's instructions. The purified fragments were then sequenced (Unidad de Síntesis y Secuenciación de AND, Instituto de BiotecnologíaUNAM), and a BLASTn analysis was performed (http:// blast.ncbi.nlm.nih.gov/Blast.cgi). In order to detect nucleotide mutations and to confirm the integrity of the sequence, we have sequenced five independent clones.

\section{In silico restriction fragment length polymorphism (RFLP) of 5.8S-ITS rDNA sequences}

Once the purified fragment of $620 \mathrm{bp}$ were sequenced, an in silico enzyme digestion with CfoI, HaeIII and Hinfl was performed with EnzymeX software and Restriction Mapper V3 (http://www.restrictionmapper.org/).

\section{Amplification by PCR of $18 \mathrm{~S}$ rRNA}

To amplify a 1565-bp product corresponding to sequence of $18 \mathrm{~S}$ rRNA of $M$. guilliermondii (GenBank accession number KJ126853), we designed the primers Mgfwd: 5'AAACTGCGAATGGCTCATTAAATCAGTT ATCG-3' and Mgrev: 5'-GCGACGGGCGGTGTGTAC AAAGG -3 '. Thermal cycling was conducted with an initial step at $95{ }^{\circ} \mathrm{C}$ for $5 \mathrm{~min}, 35$ cycles of $94{ }^{\circ} \mathrm{C}$ for $40 \mathrm{~s}, 61{ }^{\circ} \mathrm{C}$ for $1 \mathrm{~min}$ and $72{ }^{\circ} \mathrm{C}$ for $1.5 \mathrm{~min}$ and a final extension of $10 \mathrm{~min}$ at $72{ }^{\circ} \mathrm{C}$.

\section{Phylogeny reconstruction}

A phylogenetic reconstruction was performed with the 1565 bp sequence of the 18S rDNA from M. guilliermondii 01 (GenBank accession number KJ126853) and 20 sequences retrieved in a BLASTn analysis.

The phylogeny was constructed with the software tool MEGA (Molecular Evolutionary Genetics Analysis) 6.0 [23], with the method Neighbor-joining and the predicted model of Maximun Compositum Likelihood. The robustness of the trees was statistically evaluated by bootstrap analysis with 1000 iterations.

\section{Growth of $M$. guilliermondii 01}

A loopful of yeast cells was grown in a pre-inoculum of $20 \mathrm{ml}$ YPD for $14 \mathrm{~h}$ at $30{ }^{\circ} \mathrm{C}$ and $200 \mathrm{rpm}$ (LabTech 3016A, USA). Next, $100 \mathrm{ml}$ of YPD was inoculated with a starting optical density at $600 \mathrm{~nm}\left(\mathrm{OD}_{600}\right)$ (Thermo Biomate 3 IV-Vis Spectrometer, USA) of 0.1 and grown until the $\mathrm{OD}_{600}$ reached 1.0 or 1.8 (approximately $8 \mathrm{~h}$ ) under the same temperature and shaking conditions. An $\mathrm{OD}_{600}$ of 1.0 corresponds to $2.72 \times 10^{6} \mathrm{CFU} / \mathrm{ml}$, and an $\mathrm{OD}_{600}$ of 1.4 corresponds to $6.72 \times 10^{6} \mathrm{CFU} / \mathrm{ml}$.

The effect of different $\mathrm{CFU} / \mathrm{ml}$ values of $M$. guilliermondii on oocyst integrity was assessed by bioassays.

\section{Recovery of culture and supernatant of $M$. guilliermondii} A culture of M. guilliermondii was obtained as described above, and $200 \mu \mathrm{l}$ of the culture was used in each bioassay. For bioassays using the supernatant, supernatants were obtained by centrifugation at $4{ }^{\circ} \mathrm{C}$ for $15 \mathrm{~min}$ at 3,500 $g$ (17303-15, Cole Parmer, USA), and $200 \mu \mathrm{l}$ was used for anticoccidial activity bioassays. $200 \mu \mathrm{l}$ of noninoculated liquid YPD was cultivated in the same mentioned conditions and used in bioassays reactions. The supernatant of YPD medium was recovered by centrifugation and also used as negative control.

\section{Ethyl acetate extraction of supernatant}

M. guilliermondii culture supernatant $(100 \mathrm{ml})$ was extracted three times with ethyl acetate (High Purity, Mexico). Briefly, the culture was mixed with one volume of ethyl acetate and strongly shaken by hand in an extraction funnel to homogenize the mixture. The funnel was then placed in a universal mount until two phases were observed (approximately 3 to $5 \mathrm{~min}$ ). The upper phase was recovered and further extracted twice.

The final extraction volume (approximately $300 \mathrm{ml}$ ) was evaporated in a rotary evaporator (R-205, Buchi, Switzerland) at $80 \mathrm{rpm}$ and $41{ }^{\circ} \mathrm{C}$. The extract was then recovered in amber vials, dried for 4 days in an extractor hood, weighed and dissolved in approximately 20 to $30 \mu \mathrm{l}$ of dimethyl sulfoxide (DMSO, J.T. Baker, USA). Two milligrams of the supernatant extract was used in anticoccidial activity bioassays. Non-inoculated YPD was also extracted with ethyl acetate and concentrated by evaporation in the same conditions. $2 \mathrm{mg}$ of the product of this extraction resuspended in DMSO were used as negative control in bioassay reactions. In order to assess the nature of the compound extracted with ethyl acetate we performed incubation with trypsin (aqui no se las condiciones de tiempo y cantidad de enzima en que lo hizo Mayra).

\section{Intracellular proteins extraction}

Yeast cell were grown in the conditions mentioned above. After this, the culture was centrifuged for $15 \mathrm{~min}$ at 9,000 g and $4{ }^{\circ} \mathrm{C}$ and the supernatant was discarded. The pellet was recovered and resuspended in $20 \mathrm{mM}$ phosphate buffer ( $\mathrm{pH}$ 7.0). The cells were lysed by sonication for $10 \mathrm{~min}$ and $32 \%$ of amplitude (Ultrasonic processor, Sonic \& Materials) and then centrifuged for 15 min at $9,000 \mathrm{~g}$ and $4{ }^{\circ} \mathrm{C}$.

The recovered supernatant, that contained the intracellular crude extract, was filtered through a PVDF membrane (Millex GV filter unit 0.22- $\mu \mathrm{m}$, Millipore) and then quantified by the Bradford assay [24] using a standard curve of bovine serum albumin (BSA). 


\section{Proteins precipitation with ammonium sulfate}

The concentrated intracellular proteins were precipitated with 20,40, 60 and $80 \%$ of saturated solution of ammonium sulfate. This mix was stirred on ice for $2 \mathrm{~h}$ and then centrifuged at $15,000 \mathrm{~g}$ for $15 \mathrm{~min}$ at $4{ }^{\circ} \mathrm{C}$. The supernatant was discarded and the pellet was dissolved in $20 \mathrm{mM}$ phosphate buffer ( $\mathrm{pH}$ 7.0) and dialyzed overnight (12 kD dialysis tubing membrane, Sigma-Aldrich). Finally, the dialyzed fractionated proteins were concentrated by centrifugation (Amicon Ultra Concentrator with $10 \mathrm{kD}$ molecular mass cut-off, Millipore) and quantified by the Bradford assay [24] using a standard curve of bovine serum albumin (BSA). Each fraction was used in anticoccidial activity bioassays.

\section{Proteins denaturalizing treatment}

Five hundred micrograms of proteins precipitated with a $40 \%$ saturated solution of ammonium acetate were treated with a $1 / 10$ of trypsin $(1 \mathrm{mg} / \mathrm{ml}$, Sigma-Aldrich) diluted in $12.5 \mathrm{mM}$ Tris- $\mathrm{HCl}(\mathrm{pH} 9.0)$ for $12 \mathrm{~h}$ at $37{ }^{\circ} \mathrm{C}$. After this, proteins were incubated for $10 \mathrm{~min}$ at room temperature and then $10 \mathrm{~min}$ on ice. To stop the reaction, $100 \mathrm{mM}$ of PMSF (phenylmethanesulfonylfluoride) protease inhibitor (Sigma-Aldrich) was added in a $2 \mathrm{mM}$ final concentration; the reaction was mixed by inversion and kept on ice until use.

For samples treated with trichloroacetic acid (TCA), $1,500 \mu \mathrm{g}$ of $40 \%$ fractionated proteins were precipitated with 1 volume of cold TCA $20 \%$ and mixed by inversion before incubate $20 \mathrm{~min}$ on ice. The mix was agitated by inversion several times and then centrifuged at 15,000 g for $15 \mathrm{~min}$. The pellet was washed three times with $500 \mu \mathrm{l}$ of cold acetone with intervals of centrifugation at $15,000 \mathrm{~g}$ for $10 \mathrm{~min}$. Finally, once the acetone was evaporated; the pellet was resuspended in $10 \mathrm{mM}$ Tris- $\mathrm{HCl}$ to neutralize the $\mathrm{pH}$ and $20 \mathrm{mM}$ phosphate buffer ( $\mathrm{pH}$ 7.0) was added to a final volume of $1 \mathrm{ml}$.

Separately, 1,500 $\mu \mathrm{g}$ of the $40 \%$ fraction recovered after ammonium sulfate precipitation were heated for $15 \mathrm{~min}$ at $95^{\circ} \mathrm{C}$ and then kept on ice for $15 \mathrm{~min}$.

Both samples, treated with TCA and heat, were quantified and assayed for anticoccidial activity.

\section{In vitro anticoccidial activity bioassays}

Bioassays were performed using E. tenella oocyst suspensions (SENASICA) and Eimeria spp. commercial oocyst suspensions (ATD-1Coccivac B). Both oocysts suspensions consisted of a heterogeneous mixture of unsporulated and sporulated oocyst, with a predominance of sporulated (infective).

Oocysts were washed and quantified in a Neubauer chamber (Improved Bright Line, Loptik Labor, Germany) before bioassays were performed. A $1 \mathrm{ml}$ sample of oocysts was washed three times with $1 \mathrm{ml}$ of sterile injectable water (Pisa, Mexico) until the medium was clarified; centrifugation at $850 \mathrm{~g}$ for $1 \mathrm{~min}$ (Thermo Electron IEC Micromax Microcentrifuge, USA) was performed for every wash.

Under sterile conditions, bioassay reactions were prepared in $1.5 \mathrm{ml}$ Eppendorf tubes containing 100,000 E. tenella oocysts along with $200 \mu \mathrm{l}$ of M. guilliermondii culture, $200 \mu \mathrm{l}$ of supernatant, $2 \mathrm{mg}$ of ethyl acetate supernatant extract, $300 \mu \mathrm{g}$ of intracellular proteins, $300 \mu \mathrm{g}$ of $40 \%$ fraction precipitated with ammonium sulfate or $300 \mu \mathrm{g}$ of $40 \%$ fraction treated with trypsin.

For the bioassays performed with culture and supernatant the final volume was $1 \mathrm{ml}$ adjusted with injectable water. Bioassay reactions with ethyl acetate supernatant extracts were prepared in $1.5-\mathrm{ml}$ tubes with 100,000 oocysts and $2 \mathrm{mg}$ of extract dissolved in DMSO (final concentration $2 \%, 20 \mu \mathrm{l}$ ), and the reactions were brought to $1 \mathrm{ml}$ with injectable water as is shown in Additional file 1. On the contrary, all bioassays performed with intracellular proteins and $40 \%$ fractions (with or without trypsin) were adjusted to $1 \mathrm{ml}$ with $20 \mathrm{mM}$ phosphate buffer ( $\mathrm{pH}$ 7.0). Bioassays reactions were incubated at $30{ }^{\circ} \mathrm{C}$ and $200 \mathrm{rpm}$ (LabTech 3016A, USA) and then observed microscopically after 24 and $48 \mathrm{~h}$ of incubation. Oocysts from the reactions were counted in a Neubauer chamber at 0,24 and $48 \mathrm{~h}$. Oocyst integrity was assessed microscopically (Leica DM750), an oocyst wall without damage was considered as a viable and infective oocyst, whereas an oocyst wall with the slightest damage was considered as non-viable and therefore noninfective oocyst.

The amount, $2 \mathrm{mg}$ of ethyl acetate extract allows observing clearly the damage of the extract on oocysts in a determined period of time. Higher amounts of compound causes that damage in oocysts is not accurately observable; lower amounts extends the time of observation and damage is barely noticeable in a determined period of time.

Depending on the case, control reactions were prepared with only 100,000 oocysts, $200 \mu \mathrm{l}$ of YPD medium, or supernatant of YPD medium and injectable water (up to $1 \mathrm{ml}$ ). As regards to control reaction in bioassays containing ethyl acetate extract, it contained, 100,000 oocysts, ethyl acetate extract of YPD medium resuspended in DMSO and injectable water (up to $1 \mathrm{ml}$ ). Control reaction of intracellular crude extract and $40 \%$ ammonium sulfate fractions contained 100,000 oocysts and phosphate buffer $20 \mathrm{mM} \mathrm{pH} 7.2$ (up to $1 \mathrm{ml}$ ). Control reactions were incubated under the same temperature and shaking conditions.

All experiments were standardized with respect to controls, so the standard deviation is not plotted. Independent triplicates were performed for each bioassay. 


\section{Statistical analysis}

All statistical analyses were performed with Minitab ${ }^{\circ} 15$ Statistical Software. A one-way analysis of variance was used to analyze the differences in mortality among the different bioassays. To determine significant differences among the means, a Tukey test was performed. The significance threshold was set at $P<0.05$.

\section{Results}

\section{BLAST analysis}

We performed a BLASTn search with the M. guilliermondii 5.8S-ITS rDNA and D1/D2 domain sequences to find similarities with reported sequences.

The 620-bp 5.8S-ITS rDNA query sequence showed $100 \%$ sequence identity with Pichia guilliermondii (FJ515181.1), 99 \% with Meyerozyma guilliermondii (JQ425356.1, HQ693808.1) and 99 \% with Pichia guilliermondii (EF222226.1, 197816.1).

A similar result was obtained for a 632-bp D1-D2 domain sequence (GenBank accession KJ126855). BLASTn analysis showed 99 \% sequence identity with Pichia guilliermondii (EJ515181.1, FJ969194.1, EU569871.1) and Meyerozyma guilliermondii (JQ425356.1, HQ693807.1). The percentages of query coverage in these analyses ranged from 98 to $99 \%$.

\section{In silico restriction analysis of 5.8S-ITS rDNA}

An in silico enzymatic digestion of the 620-bp sequence (GenBank accession number KJ126854) corresponding to the 5.8 ITS rDNA region was performed with CfoI, HaeIII and HinfI, and all the predicted fragments coincided with those reported by [20].

EnzymeX and RestrictionMapper digestion predicts CfoI fragments of 314 and $255 \mathrm{bp}$, HaeIII fragments of 392, 108 and $87 \mathrm{bp}$ and HinfI fragments of 335 and $277 \mathrm{bp}$.

\section{Molecular identification of Meyerozyma guilliermondii 01}

A 1565-bp sequence from the $18 \mathrm{~S}$ rDNA region of $M$. guilliermondii (GenBank accession number KJ126853) was used to construct a phylogeny with 20 sequences retrieved by BLASTn. Sample results from this analysis include $100 \%$ identity with M. guilliermondii (KC178873.1) and P. guilliermondii (DQ821711.1), $99 \%$ identity with $P$. caribbica (EF194890.1).

The phylogenetic tree shows that the yeast isolated from oocysts is grouped with $P$. guilliermondii and $M$. guilliermondii. A representative tree is shown in Fig. 1. We followed the new genera proposed by Kurtzman and Suzuki [25], in which the authors indicate that the species $P$. guilliermondii and P. caribbica now belong to the genus Meyerozyma.

\section{Dose-effect analysis of $M$. guilliermondii 01 on Eimeria spp. oocysts}

Bioassays performed with a culture of $M$. guilliermondii 01 showed that oocyst integrity decreased as higher $\mathrm{OD}_{600}$ of culture were used. After $48 \mathrm{~h}$ of co-incubation, oocyst integrity had decreased to $53.90 \%$ of its original value for $\mathrm{OD}_{600}$ of $1.0\left(2.72 \times 10^{6} \mathrm{CFU}\right)$ of $M$. guilliermondii, whereas a decrease to $35.20 \%$ was observed for $\mathrm{OD}_{600} 1.4\left(6.72 \times 10^{6} \mathrm{CFU}\right)$. Controls (without yeast) at 24 and $48 \mathrm{~h}$ showed a decrease in integrity to $85.43 \%$ and $82.09 \%$ of the original values, respectively (Fig. 2). Statistical analysis showed significant difference among control and $\mathrm{OD}_{600} 1.0,1.2,1.4,1.6$ and 2.0 at 24 and 48 h (Fig. 2).

Controls (without yeast) at 24 and $48 \mathrm{~h}$ showed a decrease in integrity to 85.43 and $82.09 \%$ of the original values, respectively (Fig. 2).

Damage to oocyst walls was observed microscopically. Control oocysts maintained their integrity; this is, displaying a double-layered structure with rounded, intact, light-reflective walls. Damaged oocysts displayed a structurally disturbed wall and in some cases showed sporozoites outside the oocyst. In most of the observations, a decrease was detected in the number of oocysts, and only structural lysis was observed (Fig. 3).

\section{Anticoccidial activity of culture, supernatant and ethyl acetate extract of $M$. guilliermondii 01}

Oocyst wall integrity was assessed 0,24 and $48 \mathrm{~h}$ after adding M. guilliermondii 01 supernatant, culture and ethyl acetate extract. It is noteworthy to mention that the ethyl acetate extract have been previously treated with trypsin and anticoccidial activity remained the same, which suggest that the compound with anticoccidial activity in the extract is not of protein nature.

After $24 \mathrm{~h}$ of incubation, the anticoccidial activity of whole yeast culture on Eimeria tenella oocysts reduced their wall integrity to $45.16 \%$, whereas the integrity of oocyst walls after incubation with supernatant was $61.50 \%$. Oocyst integrity further decreased after $48 \mathrm{~h}$ of incubation, to 22.16 and $42.40 \%$ of their original values with culture and supernatant, respectively. The integrity of the controls remained at 92.96 and $88.96 \%$ after 24 and $48 \mathrm{~h}$ incubation, respectively (Fig. 4).

Ethyl acetate extracts of yeast culture supernatants showed anticoccidial activity against oocysts after 24 and $48 \mathrm{~h}$ of incubation. A 2.6 -fold decrease in oocyst integrity was observed over the first $24 \mathrm{~h}$ of incubation (38.05\% integrity), and integrity further decreased by 2 -fold between 24 and $48 \mathrm{~h}$ (18.90\% integrity) (Fig. 4).

\section{Anticoccidial activity of proteins}

Anticoccidial activity of intracellular proteins was also assessed. After $24 \mathrm{~h}$ of incubation $61 \%$ of oocysts 


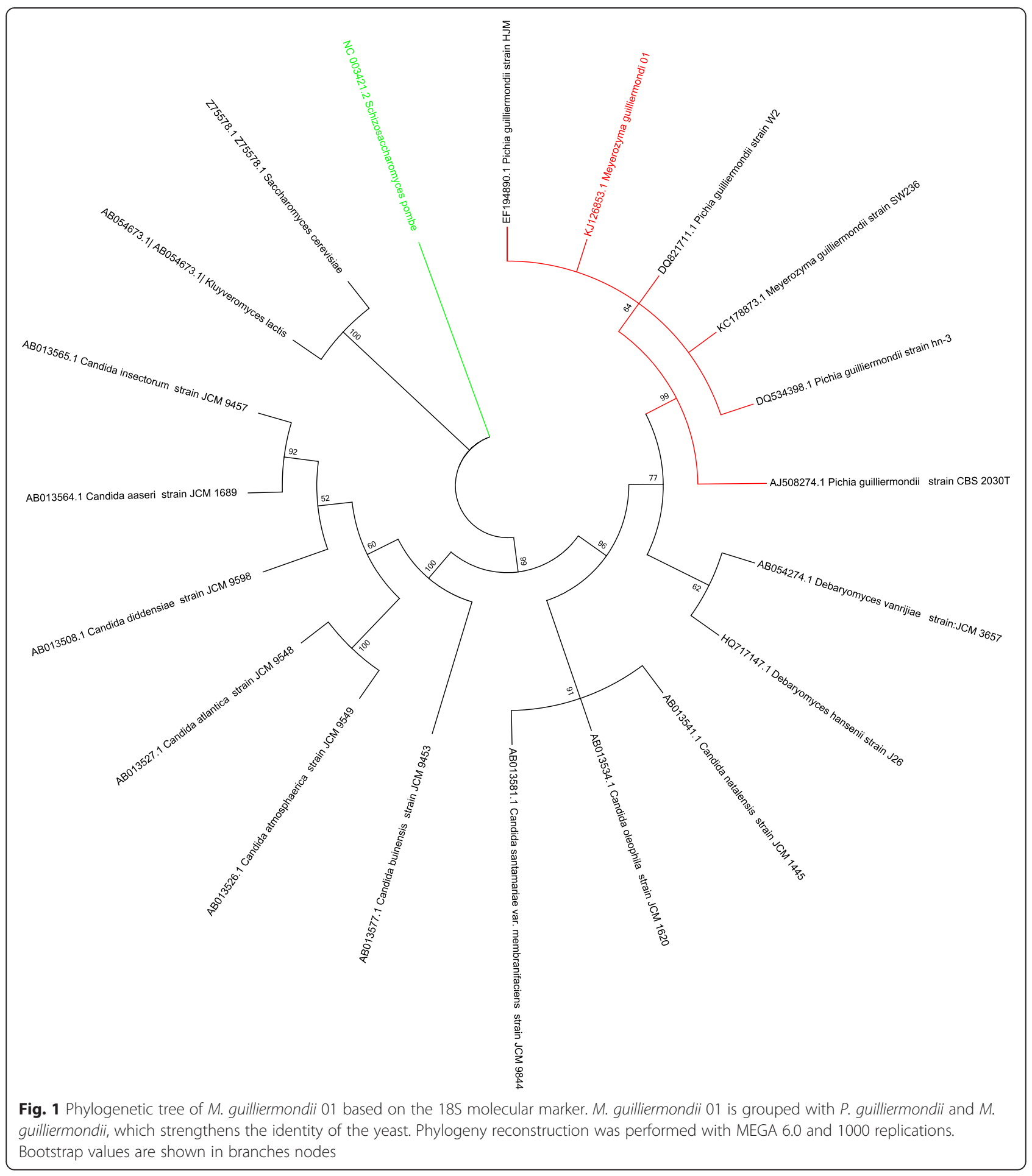

maintained its integrity and decreased 1.3 fold after $48 \mathrm{~h}$ (Fig. 4).

The fraction precipitated with $40 \%$ of ammonium sulfate maintained $61.74 \%$ of oocyst integrity at 24 and $44.06 \%$ of integrity at $48 \mathrm{~h}$ of incubation, whereas the same fraction treated with trypsin showed 80.92 and $87.86 \%$ of integrity after 24 and $48 \mathrm{~h}$ of incubation, respectively (Fig. 5). No significant differences were observed between intracellular crude extract and $40 \%$ fraction precipitated with ammonium sulfate, but a significant difference it was observed with respect to $40 \%$ fraction precipitated with ammonium sulfate treated with trypsin. According to this, the effect of trypsin is clearly affecting the compound with anticoccidial activity present in the $40 \%$ fraction. 


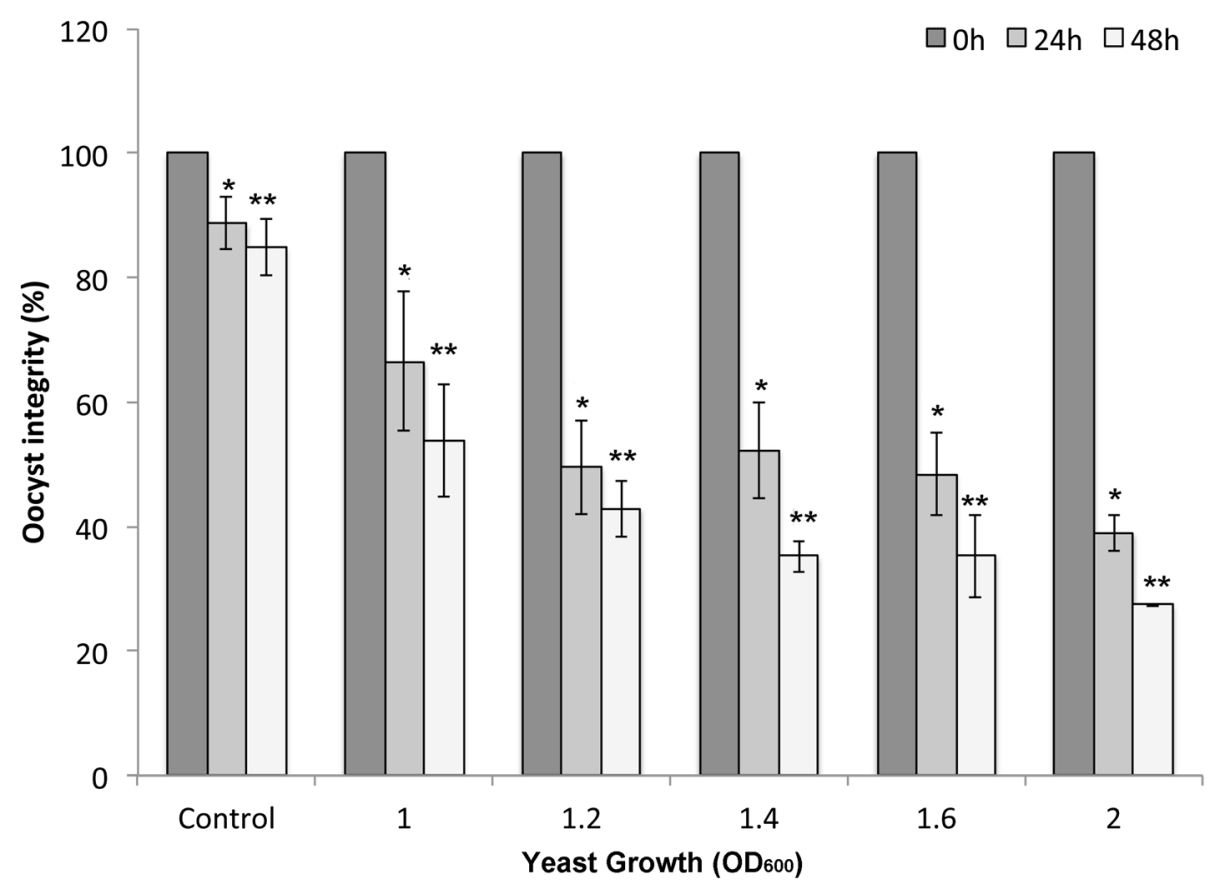

Fig. 2 Anticoccidial activity M. guilliermondii 01 on E. tenella oocysts at increasing optical densities $\left(\mathrm{OD}_{600}\right)$. After $48 \mathrm{~h}$, with a higher number of cells at $\mathrm{OD}_{600}$, a more lethal anticoccidial activity was observed. Significant differences among control and $24 \mathrm{~h}$ are shown with an asterisk and significant differences among control and $48 \mathrm{~h}$ are shown with double asterisk (significance threshold, $P<0.05$ )

\section{Discussion}

The complex ITS regions ITS1 and ITS2 (non-coding and variable) and the $5.8 \mathrm{~S}$ rRNA gene (coding and conserved) were useful for measuring close fungal phylogenetic relationships, as they exhibit far greater interspecific differences than the $18 \mathrm{~S}$ and $26 \mathrm{~S}$ rRNA genes [26].

Our in silico RFLP analysis of the 5.8S-ITS rDNA region showed a restriction pattern that matched the pattern reported for Pichia guilliermondii by [20]. In addition to this species, Meyerozyma guilliermondii was also found among the BLASTn results retrieved with the 5.8S-ITS rDNA region and D1/D2 domain.

The most common methods used for the identification of yeast species are based on the variability of the $5.8 \mathrm{~S}$, $18 \mathrm{~S}$ and 26S ribosomal genes [27]. However, Kurtzman and Suzuki (2010) recently conducted a phylogenetic analysis of combinations of the D1/D2 domains of the large subunit and small subunit rRNA genes from budding ascomycetous yeast. These authors proposed five new genera: Babjeviella, Millerozyma, Priceomyces, Scheffersomyces and Meyerozyma. They proposed the name Meyerozyma guilliermondii (comb. nov. MycoBank no. MB513463) instead of the basionym Pichia guilliermondii [28].

Based on the phylogeny and other bioinformatic analyses, and because we have adopted this new proposed classification, we identified the anticoccidial yeast isolated from Eimeria oocysts as Meyerozyma guilliermondii.
The in vitro anticoccidial activity of this yeast was assessed in bioassays using E. tenella oocysts.

The effect of the active anticoccidial compound(s) was observed not only against $E$. tenella oocysts but also against other Eimeria species (E. tenella, E. maxima, E. acervulina, E. praecox) that showed similar results with respect to oocyst integrity and cell damage as is shown in Additional file 2.

We observed that increasing values of optical density $\left(\mathrm{OD}_{600}\right)$ of yeast were associated with major damage to the oocyst, as higher $\mathrm{OD}_{600}$ counts in a bioassay corresponded to greater anticoccidial activity, a clearly dose-dependent effect. Besides, damage to the oocyst walls was evident $24 \mathrm{~h}$ after incubation and at $48 \mathrm{~h}$, when cellular debris appeared. It is noteworthy that the compound(s) of $M$. guilliermondii culture can break the wall of sporulated and unsporulated oocysts.

This activity was observed not only with different $\mathrm{OD}_{600}$ values of whole yeast culture but also with culture supernatants. In this case, whole yeast culture and ethyl acetate extract showed the greatest activity against oocysts, with supernatant and intracellular crude extract showing less activity, indicating that the presence of yeast cells increases anticoccidial activity. Because activity was observed in whole yeast culture and in supernatants, the compound(s) that possess anticoccidial activity may be secreted by yeast. 


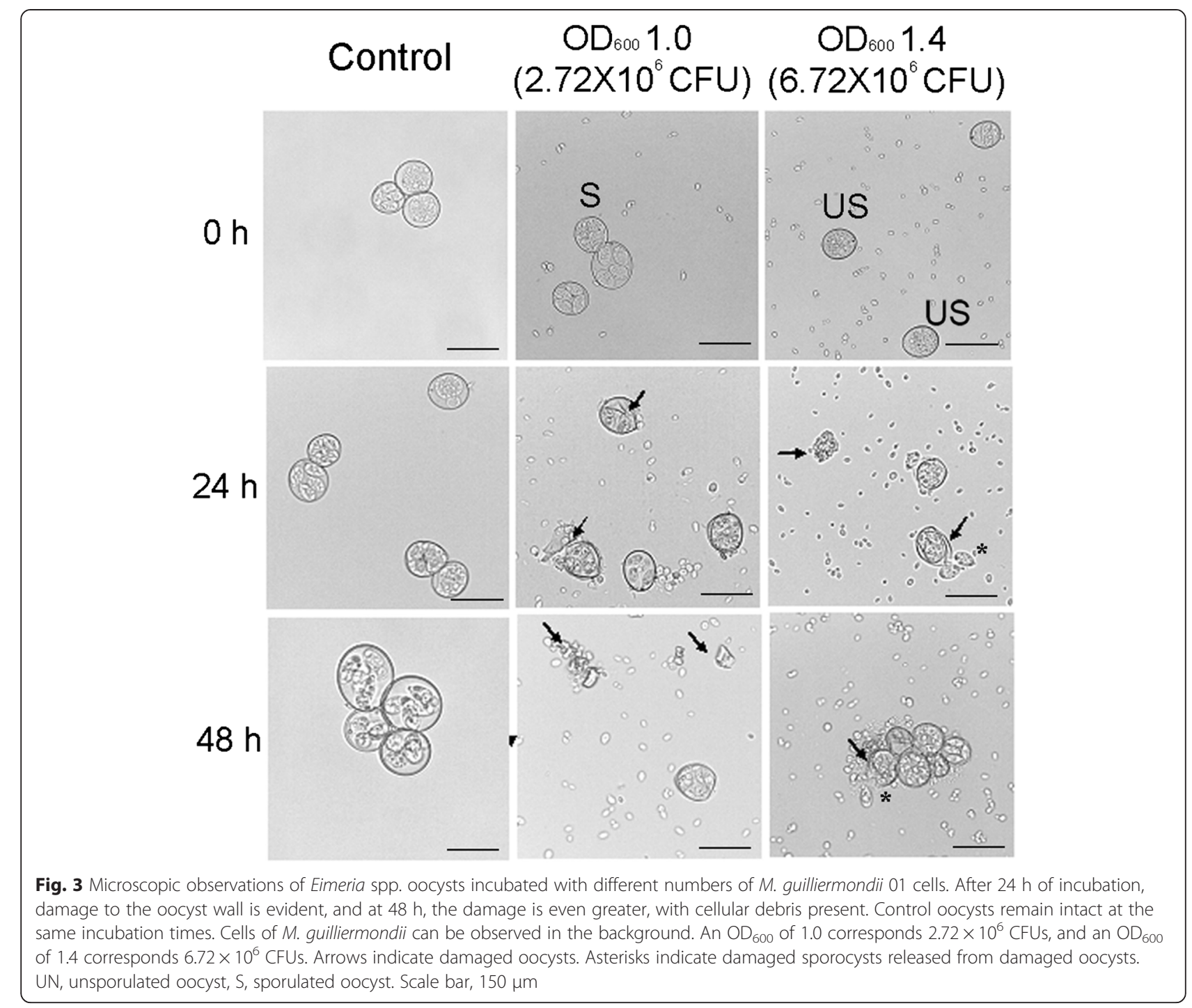

When incubated in vitro with $2 \mathrm{mg} / \mathrm{ml}$ of the ethyl acetate extract for $24 \mathrm{~h}$, we observed $61.95 \%$ of damaged oocysts and $81.10 \%$ at $48 \mathrm{~h}$. Although the characteristics of the active anticoccidial compound(s) remain unknown, we suggest that it may have a polar nature because ethyl acetate has a polarity index of 4.4 and is generally considered a polar solvent (Fig. 4). Something similar was observed by A Remmal, S Achahbar, L Bouddine, N Chami and F Chami [16], they highlighted the activity of $4 \mathrm{mg} / \mathrm{ml}$ artemisia, thyme, clove and tea tree EO against 100,000 oocysts. After $25 \mathrm{~h}$ of incubation, this concentration induced approximately $80 \%$ reduction in oocyst number.

Although essential oils showed a significant decrease in oocyst integrity, we only require half of the amount of our compound(s) extracted with ethyl acetate to observe a significant decrease in the number of oocysts. On the other hand, the economic factor involve in the production of essential oils make them an expensive alternative.

Recently, a product known as CitriStim (ADM Alliance Nutrition), that is a whole yeast co-product of citric acid extraction, containing the whole yeast and its components was used as a supplement in broiler production parameters and for immune responses during experimental coccidial infection. Researchers found that fecal oocysts diminished at 7 days post-coccidial infection, indicating accelerated clearance of coccidian [29].

We performed bioassays using CitriStim against $E$. tenella oocysts and against other species, but we did not find any significant damage to the oocyst walls or decreased numbers of intact oocysts after incubating for 24 and $48 \mathrm{~h}$ (data not shown).

The absence of activity by the yeast strain present in CitriStim could be explained by its identity as a different 


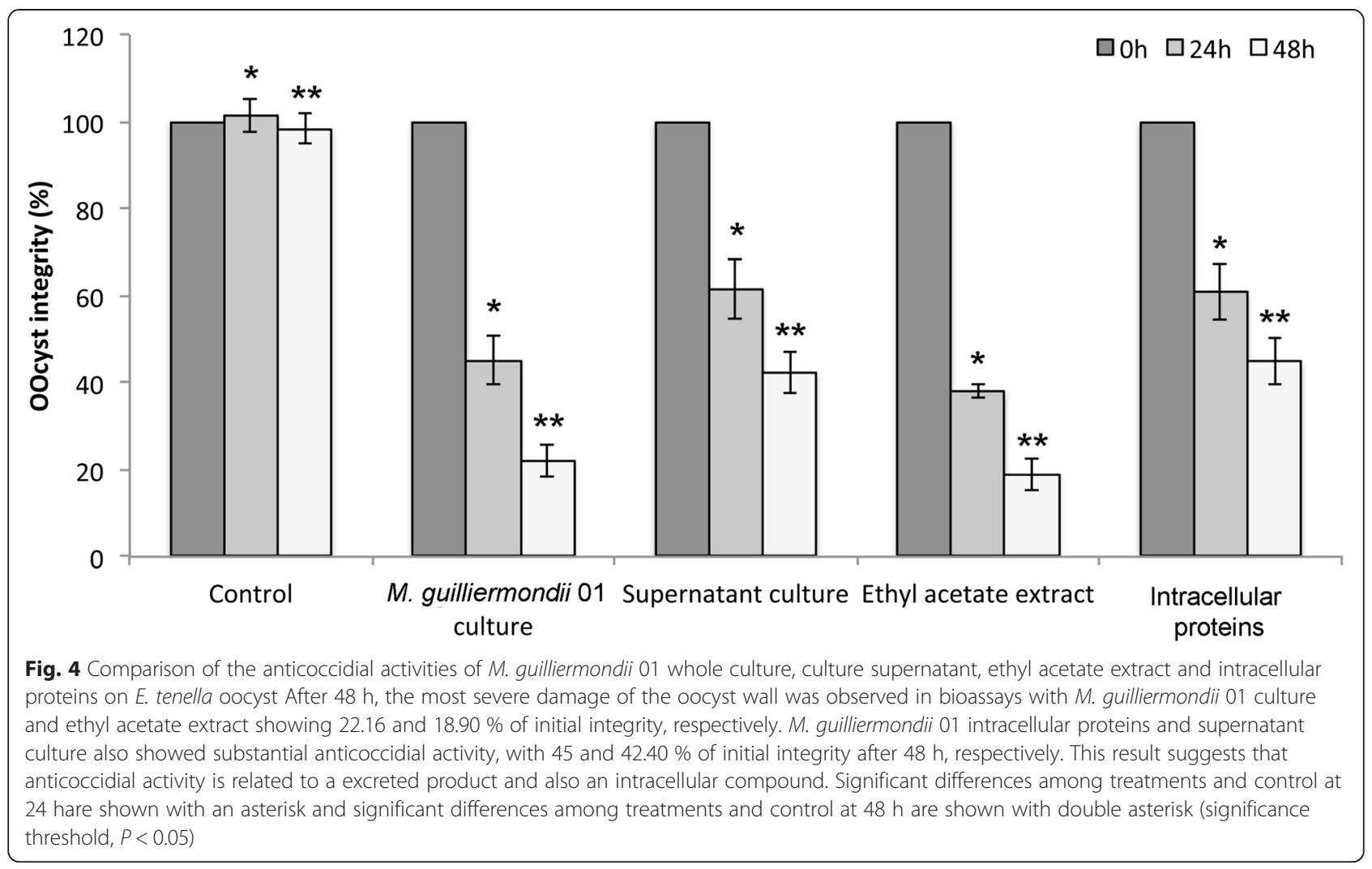

strain of M. guilliermondii that was possibly isolated from a different site.

A bioinformatic analysis performed (pairwise sequence alignment, EMBOSS Neddle) between $18 \mathrm{~S}$ rDNA sequences showed only $73.5 \%$ of identity between both yeasts. Studies of the genomic differences between these strains might elucidate the mechanism of anticoccidial action.

We analyzed the activity of our strain against different cells, including Escherichia coli K-12, Saccharomyces cerevisiae and KB human cells, but we did not find activity against any of them, suggesting that the activity is specific to Eimeria. This mayx not be the only activity of $M$. guilliermondii since it has been reported that the helvolic acid isolated from the culture of this yeast exerts an inhibitory activity on the spore germination of fungi Magnaporthe oryzae [30].

In our case, the obtained results are of great significance for future applications, especially after further in vivo analysis in chickens.

Although coccidiosis can be controlled with the use of anticoccidial drugs and with first-, second- and, recently, third-generation vaccines, none of these options are completely satisfactory; therefore, new alternatives are required. Our data show the effectiveness of M. guilliermondii 01 culture, culture supernatant and supernatant extract for damaging E. tenella oocysts. The results suggest that this yeast, isolated in oocyst suspensions from infected chickens, has important anticoccidial activity as shown in bioassays and could be used as a potent disinfectant of poultry environments.

An in vivo bioassay with chickens using anticoccidial compound(s) of M. guilliermondii 01 should be performed to enlighten the potential activity of this yeast. An interesting characteristic of M. guilliermondii 01 is that culture, supernatant or ethyl acetate extract are not the only that showed anticoccidial activity, but also intracellular proteins. In order to assess anticoccidial activity of excreted proteins we precipitated them from the supernatant and performed bioassays. However, no anticoccidial activity was observed (data not shown). The observed anticoccidial activity of intracellular crude extract suggests that the compound responsible of this activity is a protein. This was confirmed when we performed the bioassays using the precipitated proteins with $40 \%$ of ammonium sulfate treated with trypsin. Additionally, we assessed the effect of trichloroacetic acid and heat on the $40 \%$ fraction. After 24 and $48 \mathrm{~h}$ of incubation, $40 \%$ fraction precipitated with TCA showed 93 and $99 \%$ of integrity and the $40 \%$ fraction that was heated showed 90 and $99 \%$ of integrity at the same times as is shown in Additional file 3. This result supports the idea of a compound of proteic nature capable of destroy the oocyst wall, a two walls structure mainly 


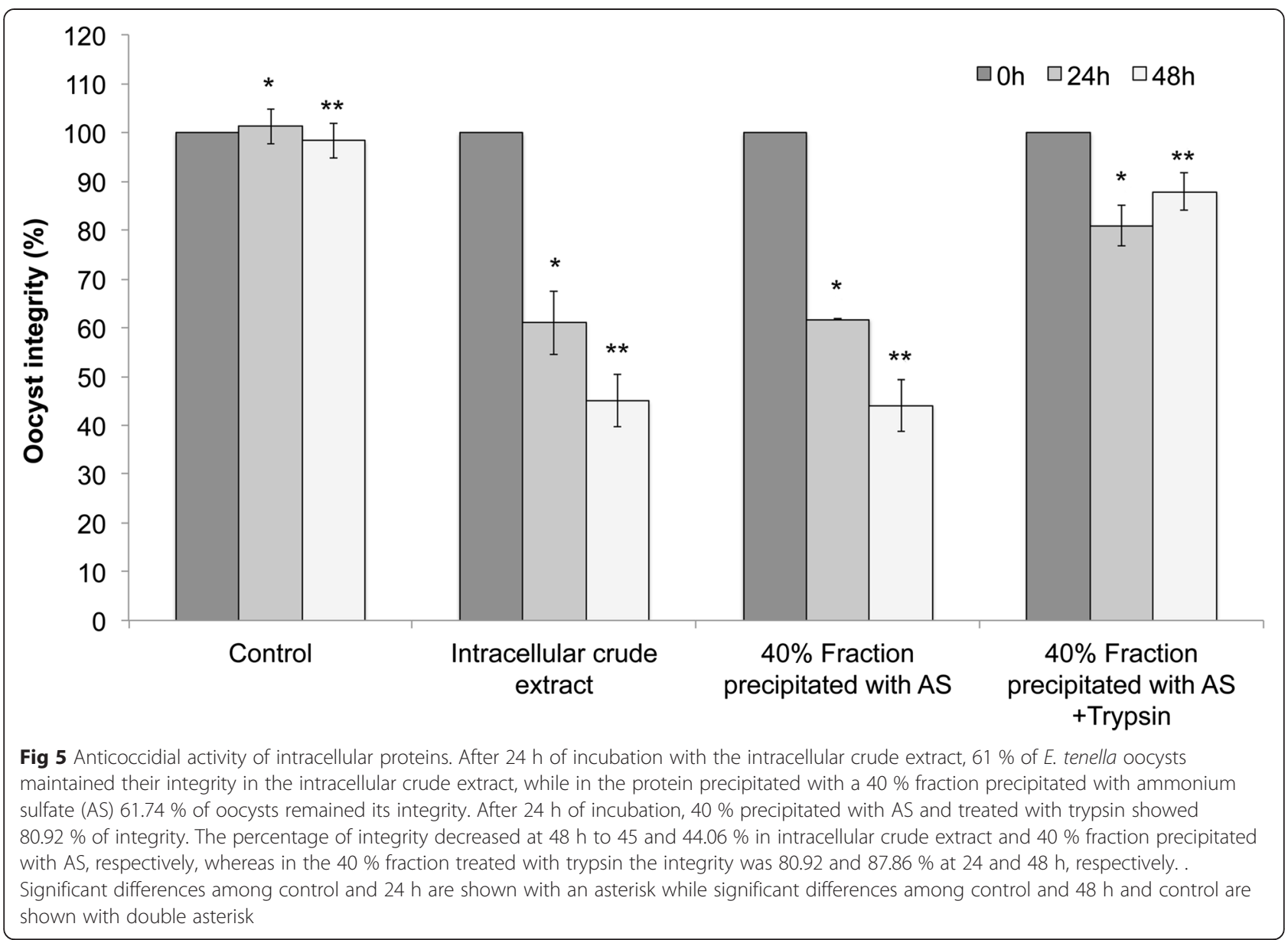

composed by proteins, lipids and levels of carbohydrate covalently bounded to proteins, however, the composition of each layer is still unclear. If this compound cause damage to outer cell wall, it should be attacking a wall composed of quinone-tanned protein, as well as proteintyrosine crosslinks [10].

We are now actively trying to identify the compound(s) that possess the observed anticoccidial activity in search of new products that can help to control the infection and dispersion stage of avian coccidiosis.

\section{Conclusions}

We report here the damage to oocysts walls caused by M. guilliermondii culture, supernatant, supernatant extract and intracellular proteins. Our data from in vitro assays, suggest that anticoccidial activity of $M$. guilliermondii 01 is due to the excretion of a metabolite as well as proteic component. In both cases, a decreased number of oocysts were observed since a significant oocysts lost their viability because of the damage caused by the yeast products. The next step is to perform in vivo assays with the metabolite or protein treated oocyst, so far, the reported here shows the potential of this yeast and its products as a feasible method of coccidiosis control.

\section{Additional files}

Additional file 1: Effect of DMSO on anticoccidial activity. Bioassays were performed with E. tenella oocysts incubated with different percentages of DMSO (2 and $4 \%$ ) and ethyl acetate extract. Neither 2 nor $4 \%$ of DMSO shown any effect on oocysts integrity after $48 \mathrm{~h}$. On the contrary, oocysts treated with ethyl acetate extract showed almost $20 \%$ of integrity after $48 \mathrm{~h}$. This, strongly suggest that DMSO has a negligible effect on oocysts integrity. Significant differences among DMSO 2 and $4 \%$ and ethyl acetate extract are shown with an asterisk; significant differences among DMSO 2 and $4 \%$ and ethyl acetate extract are shown with double asterisk (significance threshold, $P<0.05$ ). (TIFF $481 \mathrm{~kb}$ )

Additional file 2: Anticoccidial activity of M. guilliermondii on Eimeria sp. oocyst. After $48 \mathrm{~h}$ of incubation the anticoccidial activity values of the culture, supernatant, ethyl acetate extract and intracellular proteins decreased 1.17, 1.28, 1.26 and 1.02-fold, respectively. There are not significant differences between treatments (significance threshold, $P<0.05$ ). (TIFF $94 \mathrm{~kb}$ )

Additional file 3: Anticoccidial activity of $\mathbf{4 0} \%$ fraction treated with trypsin or heat. $40 \%$ fraction precipitated with ammonium sulfate and treated with TCA showed similar values of integrity that heated $40 \%$ fraction. There are not significant differences between treatments (significance threshold, $P<0.05$ ). (TIFF $237 \mathrm{~kb}$ ) 


\section{Abbreviations}

mm: Milimeters; g: Grams; L: Liter; h: Hours; ITS: Intergenic Sequence; rDNA: Ribosomal DNA; rRNDAm: Ribosomal RNA; OD: Optical density; CFU: Colony-Forming Unit; ml: Mililiters; $\mu$ l: Microliters; kD: KiloDalton; mM: Milimolar; $\mu \mathrm{g}$ : Micrograms; rpm: Revolutions per minute.

\section{Competing interests}

The authors declare that there is no conflict of interest, whether financial or non-financial, regarding the publication of this paper.

\section{Authors' contributions}

EDG, REQC, MCC, YGM, LOH carried out the laboratory studies; JVH, carried out the laboratory studies and performed the statistical analysis; REQC contributed to preparation of the manuscript; EDG, designed and coordinated the study, and led preparation of manuscript; JRTV, LSC carried out laboratory studies and made the production of yeast; EDG, LOH carried out project financing. All authors have read and approved the final manuscript.

\section{Acknowledgments}

The authors want to thank to Nahim Salgado Medrano for his collaboration in the isolation of the yeast. This work was supported by Consejo Nacional de Ciencia y Tecnología (CONACyT) project CB-2012-182225 and Universidad Autónoma del Estado de Morelos (UAEM)-(CONACyT) Technology Development Project Phase Prototyping UAEM/CONACYT_EDantan13_01. A scholarship from CONACYT to J.V.H. (289436); and a postdoctoral CONACYT fellowship to R.E.Q.C (No. 47895).

\section{Author details}

'Laboratorio de Investigaciones Ambientales-Centro de Investigación en Biotecnología, Universidad Autónoma del Estado de Morelos, Cuernavaca, Morelos, Mexico. ${ }^{2}$ Unidad de Anaplasmosis del CENID-Parasitología Veterinaria, Instituto Nacional de Investigaciones Forestales, Agrícolas y Pecuarias, Juitepec, Morelos, Mexico. ${ }^{3}$ Facltad de Ciencias Biológicas, Universidad Autónoma del Estado de Morelos, Cuernavaca, Mexico. ${ }^{4}$ Unidad de Escalamiento y Planta Piloto-Instituto de Biotecnología, Universidad Nacional Autónoma de México, Cuernavaca, Morelos, Mexico.

Received: 7 April 2015 Accepted: 30 October 2015

Published online: 09 November 2015

\section{References}

1. Wiedmer S, Stange J, Kurth T, Bleiss W, Entzeroth R, Kurth M. New insights into the excystation process and oocyst morphology of rodent Eimeria species. Protist. 2011:162:668-78.

2. Lal K, Bromley E, Oakes R, Prieto JH, Sanderson SJ, Kurian D, et al. Proteomic comparison of four Eimeria tenella life cycle stages: unsporulated oocyst, sporulated oocyst, sporozoite and second generation merozoite. Proteomics. 2009:9(19):4566-76.

3. McDonald V, Shirley MW. Past and future: vaccination against Eimeria. Parasitology. 2009;136:1477-89.

4. Blake D, Tomley FM. Securing poultry production from the ever-present Eimeria challenge. Trends Parasitol. 2014;30(1):12-9.

5. Dalloul RA, Lillehoj HS. Recent advances in immunomodulation and vaccination strategies against coccidiosis. Avian Dis. 2005;49:1-8

6. Gilbert ER, Cox CM, Williams PM, McElroy AP, Dalloul RA, Ray WK, et al. Eimeria species and genetic background influence the serum protein profile of broilers with coccidiosis. PLoS One. 2011;6(1):e14636.

7. Haug A, Gjevre AG, Thebo P, Mattsson JG, Kaldhusdal M. Coccidial infections in commercial broilers: epidemiological aspects and comparison of Eimeria species identification by morphometric and polymerase chain reaction techniques. Avian Pathol. 2008:37:161-70.

8. McDougald LR. Protozoal Infections. In: Saif YM, Barnes HJ, Glisson JR, Fadly AM, McDougald LR, Swayne DE, editors. Diseases of poultry. Ames, IA, USA lowa State University Press; 2003. pp. 973-1023.

9. Norton CC, Chard MJ. The oocyst sporulation time of Eimeria species from the fowl. Parasitology. 1983;86:193-8.

10. Belli SI, Smith NC, Ferguson DJ. The coccidian oocyst: a tough nut to crack! Trends Parasitol. 2006:22:416-23.

11. Mai K, Sharman PA, Walker RA, Katrib M, De Souza D, McConville MJ, et al. Oocyst wall formation and composition in coccidian parasites. Mem Inst Oswaldo Cruz. 2009;104(2):281-9.
12. Schares G, Pantchev N, Barutzki D, Heydorn AO, Bauer C, Conraths FJ. Oocysts of Neospora caninum, Hammondia heydorni, Toxoplasma gondii and Hammondia hammondi in faeces collected from dogs in Germany. Int J Parasitol. 2005:35:1525-37.

13. Chapman HD, Jeffers TK, Williams RB. Forty years of monensin for the control of coccidiosis in poultry. Poultry Sci. 2010;89:1788-801.

14. Abbas RZ, lqbal Z, Blake D, Khan MN, Saleemi MK. Anticoccidial drug resistance in fowl coccidia: the state of play revisited. World's Poul Sci J. 2011;67(2):337-50

15. Remmal A, Achahbar S, Bouddine L, Chami F, Chami N. Oocysticidal effect of essential oil components against chicken Eimeria oocysts. Int J Vet Med. 2013;2013:599816.

16. Remmal A, Achahbar S, Bouddine L, Chami N, Chami F. In vitro destruction of Eimeria oocysts by essential oils. Vet Parasitol. 2011;182:121-6.

17. Abbas RZ, Colwell DD, Gilleard J. Botanicals: an alternative approach for the control of avian coccidiosis. World's Poul Sci J. 2012;68(2):203-15.

18. Bozkurt M, Selek N, Küçükyilmaz K, Eren H, Güven E, Catli AU, et al. Effects of dietary supplementation with a herbal extract on the performance of broilers infected with a mixture of Eimeria species. Brit Poultry Sci. 2012;53(3):325-32

19. Quiroz-Castañeda RE, Dantán-González E. Control of avian coccidiosis: future and present natural alternatives. BioMed Res Int. 2015;2015:430610.

20. Villa-Carvajal M, Querol A, Belloch C. Identification of species in the genus Pichia by restriction of the internal transcribed spacers (ITS1 and ITS2) and the 5.8S ribosomal DNA gene. Antonie Van Leeuwenhoek. 2006;90(2):171-81.

21. White TJ, Bruns T, Lee S, Taylor J. Amplification and direct sequencing of fungal ribosomal RNA genes for phylogenetics. In: Innis MA, Gelfand DH, Shinsky JJ, White TJ, editors. PCR Protocols: A Guide to Methods and Applications. San Diego: Academic; 1990. p. 315-22.

22. Kurtzman CP, Robnett CJ. Identification and phylogeny of ascomycetous yeasts from analysis of nuclear large subunit (26S) ribosomal DNA partial sequences. Antonie Van Leeuwenhoek. 1998;73(4):331-71.

23. Tamura S, Stecher G, Peterson D, Filipski A, Kumar S. MEGA 6: Molecular Evolutionary Genetics Analysis Version 6.0. Mol Biol Evol. 2013;30:2725-9.

24. Bradford MM. A dye binding assay for protein. Anal Biochem. 1976;72:248-54

25. Kurtzman C, Suzuki M. Phylogenetic analysis of ascomycete yeasts that form coenzyme Q-9 and the proposal of the new genera: Babjeviella, Meyerozyma, Millerozyma, Priceomyces and Scheffersomyces. Mycoscience. 2010;51:2-14.

26. Prasad GS. Sequence anlysis of internal transcribed spacer region for phylogenetics assessment of ascomycetous yeast. In: Satyanarayana T, Johri $\mathrm{BN}$, editors. Microbial diversity current perspectives and potential applications. New Delhi: I.K. International Publishing House Pvt. Ltd; 2005.

27. Arroyo-López FN, Durán-Quintana MC, Ruiz-Barba JL, Querol A, GarridoFernández A. Use of molecular methods for the identification of yeast associated with table olives. Food Microbiol. 2006;23:791-6.

28. Wickerham LJ. Validation of the species Pichia guilliermondii. J Bacteriol. 1966;92(4):1269.

29. Shanmugasundaram R, Sifri M, Selvaraj RM. Effect of yeast cell product (CitriStim) supplementation on broiler performance and intestinal immune cell parameters during an experimental coccidial infection. Poultry Sci. 2013;92:358-63.

30. Zhao J, Mou Y, Shan T, Li Y, Zhou L, Wang M, et al. Antimicrobial metabolites from the endophytic fungus Pichia guilliermondii isolated from Paris polyphylla var. yunnanensis. Molecules. 2010;15:7961-70.

\section{Submit your next manuscript to BioMed Central and take full advantage of:}

- Convenient online submission

- Thorough peer review

- No space constraints or color figure charges

- Immediate publication on acceptance

- Inclusion in PubMed, CAS, Scopus and Google Scholar

- Research which is freely available for redistribution 